PAPers in Physics, VOL. 12, ART. 120006 (2020)

Received: 27 October 2019, Accepted: 8 August 2020

Edited by: F. Melo

Reviewed by: M. Yazdani-Pedram, Universidad de Chile, Chile

B. Rivas Quiroz, Universidad de Concepción, Chile

Licence: Creative Commons Attribution 4.0

DOI: https://doi.org/10.4279/PIP.120006

www.papersinphysics.org

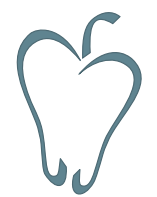

ISSN 1852-4249

\title{
The electrical and mechanical properties of cadmium chloride reinforced PVA:PVP blend films
}

\begin{abstract}
R. S. Mahmood ${ }^{1,2 *}$, S. A. Salman ${ }^{1}$, N. A. Bakr ${ }^{1 \dagger}$
In this study, pure polymer blend (PVA:PVP) film and salt $\left(\mathrm{CdCl}_{2} \cdot \mathrm{H}_{2} \mathrm{O}\right)$ reinforced polymer blend films were prepared at different weight ratios (10 wt\%, $20 \mathrm{wt} \%, 40 \mathrm{wt} \%)$ using the casting method. The effect of the salt weight ratio on the dielectric properties of the polymer blend films reinforced by $\mathrm{CdCl}_{2} \cdot \mathrm{H}_{2} \mathrm{O}$ salt were investigated, and the experimental results showed that the dielectric constant and the dielectric loss factor decreased as the frequency increased for all polymer blend films. Moreover, the above-mentioned properties increased with increasing salt weight ratios at the same frequency. The experimental results also showed an increase in AC electrical conductivity with increasing frequency, for all polymer blend films, and the AC electrical conductivity also increased with an increase in the weight ratio of the salt at the same frequency. The effect of the salt weight ratio on the mechanical properties of the salt-reinforced PVA:PVP polymer blend films was also studied. The experimental results obtained from the tensile test of the salt-reinforced polymer blend films show significant change in the values of tensile strength, elongation at break, and Young's modulus with increasing salt weight ratios; the hardness value first increases then decreases with increasing salt weight ratios, and the fracture energy value increases with increasing salt weight ratios, thus they could be good candidates for hard adhesives with low flexibility.
\end{abstract}

\section{Introduction}

Polymers such as plastics and rubbers pervade our lives, and we come across them in many different forms. Their physical properties are therefore of great importance, and an understanding of them is vital for their use in technology and engineering [1]. The blending of different polymers or inorganic ma-

*reeaheenaljana@gmail.com

†nabeelalibakr@yahoo.com

1 Department of Physics, College of Science, University of Diyala, Old Baghdad Way, Banisa'ad, Diyala, 32016 Iraq.

2 Diyala General Directorate of Education, Governorate Street, Ba'aqubah, Diyala, 32001 Iraq. terials with polymers represents a strategic route to improving the performance of a material, and allows the realization of novel composite systems that enhance the performance of the parent blend [2]. Polyvinyl alcohol (PVA) is a versatile, polyhydroxy polymeric material which has gained the interest of researchers due to its many potential applications, and the scope for easy modification and formation of useful miscible blends with many other polymers. PVA reinforced with different materials like iodine, ferric chloride, barium chloride and other salts have been studied extensively, and these polymeric materials show a significant modification in their microstructural, electrical and mechanical properties when compared to pure PVA films [3]. The subject of polymer blends has been 


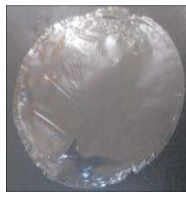

Electrical test

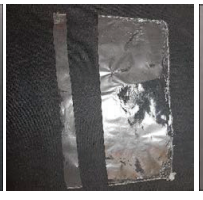

Tensile test

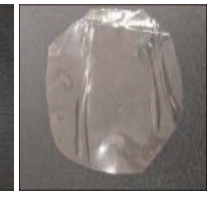

Hardness test

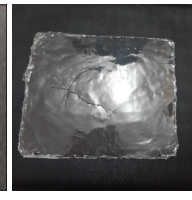

Impact test
Figure 1: The sample micrographs required for each test.

one of the primary areas of focus in polymer science and technology over several decades now. As a new area of interest in polymer science, polymer blend technology often represents an important subject [4]. Polymer blends offer versatile industrial applications through property enhancement and economic benefits. The blending of two or more polymers of similar or dissimilar natures has been practiced for many years [5]. Solution blending of different polymers is one of the methods used to obtain new material with a variety of properties, which mainly depend on the characteristics of the parent homo polymers and the blend composition [6]. Polyvinyl alcohol (PVA), a semi-crystalline polymer, has been studied widely because of its many interesting physical properties, which arise from the presence of $\mathrm{OH}$ groups and the hydrogen bond formation with other polymers or metals. Polyvinyl pyrrolidone (PVP) is a vinyl polymer possessing planar and highly polar side groups due to the peptide bond [7]. The aim of this study is to prepare pure polymer blend (PVA:PVP) film and salt $\left(\mathrm{CdCl}_{2} \cdot \mathrm{H}_{2} \mathrm{O}\right)$ reinforced polymer blend films at different weight ratios (10 wt\%, $20 \mathrm{wt} \%, 40 \mathrm{wt} \%$ ) using the casting method, and to investigate the effect of salt reinforcement on the dielectric and mechanical properties of the prepared films.

\section{Experimental work}

In the preparation of polymer blend films, polyvinyl alcohol powder (produced by Central House (P) Ltd of India with a molecular weight of $13000 \mathrm{~g} / \mathrm{mol}$ - $23000 \mathrm{~g} / \mathrm{mol})$, and Polyvinyl Pyrrolidone powder (produced by the Indian HIMEDIA Company, with a molecular weight of $40000 \mathrm{~g} / \mathrm{mol}$ ) were used. For reinforcement of the blend, cadmium chloride $\left(\mathrm{CdCl}_{2} \cdot \mathrm{H}_{2} \mathrm{O}\right)$ salt (produced by the Indian HIMEDIA Company) was used.

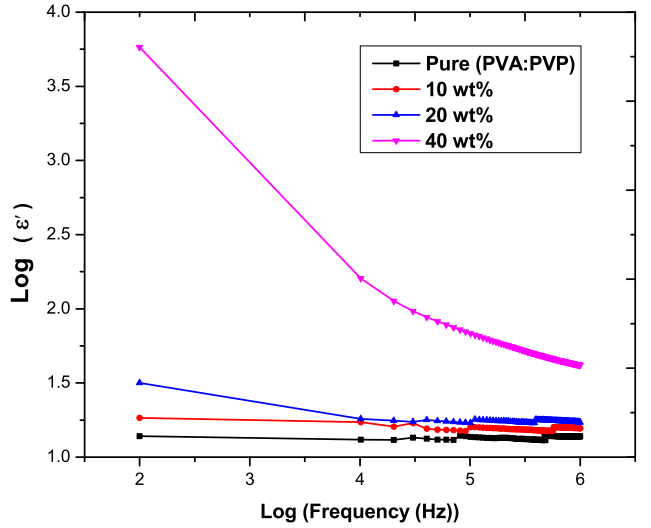

Figure 2: Log-Log plot of the dielectric constant as a function of the frequency of pure and PVA:PVP polymer blend films reinforced with different weight ratios of $\mathrm{CdCl}_{2} \cdot \mathrm{H}_{2} \mathrm{O}$ salt.

Pure PVA:PVP polymer blend film and $\mathrm{CdCl}_{2} \cdot \mathrm{H}_{2} \mathrm{O}$ salt-reinforced polymer blend films were prepared at different weight ratios (10 wt\%, 20 wt\%, 40 wt\%) using the casting method. The Differential Scanning Colorimeter (DSC) was performed for all samples and reported elsewhere, and the evidence for the blend nature of the film was confirmed [8]. The PVA and PVP powders with 1 : 1 wt\%, and $\mathrm{CdCl}_{2} \cdot \mathrm{H}_{2} \mathrm{O}$ powder with the above mentioned weight ratios were dissolved in distilled water by stirring for $1 \mathrm{hr}$ at $60{ }^{\circ} \mathrm{C}$. The solution was then poured into special glass molds placed on a flat surface and left until the solvent evaporated to obtain the pure polymer blend film and salt-reinforced polymer blend films. The thickness was measured using a digital micrometer, and was found to be in the range $1450 \mu \mathrm{m}-1455 \mu \mathrm{m}$. For the purpose of dielectric measurements, an LCR meter (4294A Agilent Precision Impedance Analyzer) was used in the frequency range of $100 \mathrm{~Hz}-1 \mathrm{MHz}$ at room temperature, and for the investigation of mechanical properties, the following instruments were used: Tinius Olsen-H10K for the tensile test, Shore D Checkline-dd-100 for the hardness test and Filling Darter Impact Tester of the type FDI-01 for the shock resistance test. Figure 1 shows the sample images required for each test. 
PAPERs In Physics, vol. 12, ART. 120006 (2020) / R. S. Mahmood et al.

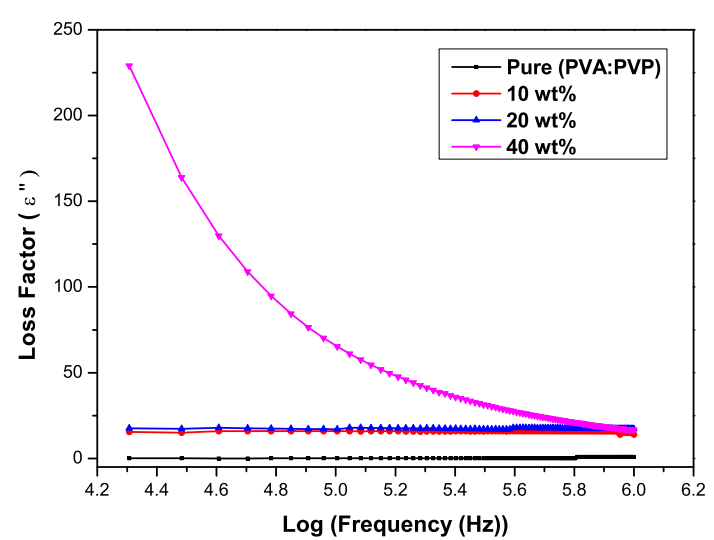

Figure 3: Semi-log plot of the loss factor as a function of the frequency of pure and PVA:PVP polymer blend films reinforced with different weight ratios of $\mathrm{CdCl}_{2} \cdot \mathrm{H}_{2} \mathrm{O}$ salt.

\section{Results and discussion}

\section{i. Electrical properties}

\section{a. Dielectric constant}

The dielectric constant $\left(\epsilon^{\prime}\right)$ was recorded for pure polymer blend PVA:PVP film and $\mathrm{CdCl}_{2} \cdot \mathrm{H}_{2} \mathrm{O}$ salt reinforced polymer blend films at different weight ratios (10 wt\%, $20 \mathrm{wt} \%, 40 \mathrm{wt} \%$ ) at room temperature and within the frequency range of $100 \mathrm{~Hz}-1$ $\mathrm{MHz}$, as shown in Fig. 2. The dielectric constant decreased with increased frequency for all polymer blend films, which can be explained as follows:

In the low frequency region there will be sufficient time for molecular dipoles to rearrange and align themselves in the direction of the external electric field, but at high frequencies the time is shorter, and less than the time period needed by the molecules for rearrangement in the direction of the external electric field [9]. The dielectric constant at the same frequency increased with an increase in the weight ratio of added salt. In general, this increase in the value of the dielectric constant is due to increased polarization [10].

\section{b. Loss factor}

The loss factor $\left(\epsilon^{\prime \prime}\right)$ is the ratio of loss of power in electrically insulating materials to the total capacity transported through the insulator; i.e., the loss

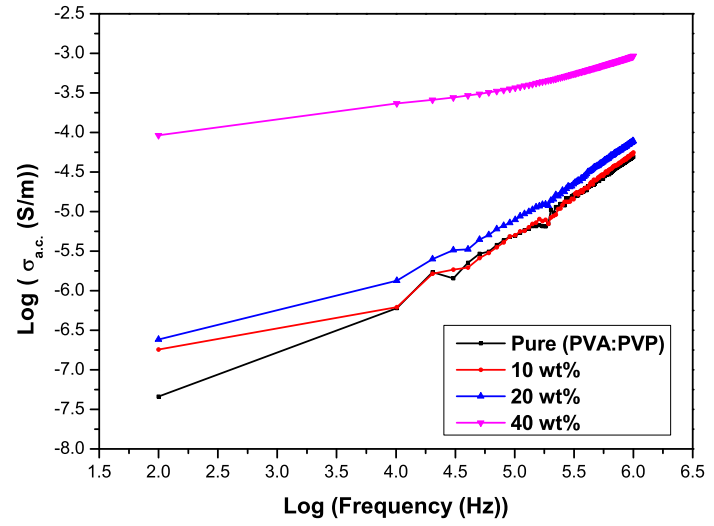

Figure 4: Log-log plot of A.C. electrical conductivity as a function of the frequency of pure and PVA:PVP polymer blend films reinforced with different weight ratios of $\mathrm{CdCl}_{2} \cdot \mathrm{H}_{2} \mathrm{O}$ salt.

of energy in the insulating material is directly proportional to the loss factor. The dielectric loss factor of the pure PVA:PVP polymer blend films and polymer blend films reinforced by $\mathrm{CdCl}_{2} \cdot \mathrm{H}_{2} \mathrm{O}$ salt was calculated at different weight ratios (10 wt\%, $20 \mathrm{wt} \%, 40 \mathrm{wt} \%$ ) at room temperature and within the frequency range of $100 \mathrm{~Hz}-1 \mathrm{MHz}$, as shown in Fig. 3. It can be observed that the loss factor decreases as the frequency increases for all the polymer blend films. This may be attributed to the enhancement of the charge carriers that takes place across the electric charge area, decreasing the value of the loss factor at high frequencies until the electron's energy is equal to the Fermi level [11]. Another reason for the change in the loss factor with frequency is the polarization mechanism and the multiple interactions between ions and dipoles. This is due to the value of relaxation time [12]. It is also observed that the value of the loss factor at the same frequency increases with an increase in the weight ratio of the added salt. In general, this increase in the value of the dielectric loss factor is attributed to the increase in polarization and the increase in ion charge carriers $[13,14]$.

\section{c. AC electrical conductivity}

The alternating electrical conductivity of the pure PVA:PVP polymer blend films and polymer blend films reinforced by $\mathrm{CdCl}_{2} \cdot \mathrm{H}_{2} \mathrm{O}$ salt was measured 
PAPers in Physics, vol. 12, ART. 120006 (2020) / R. S. Mahmood et al.
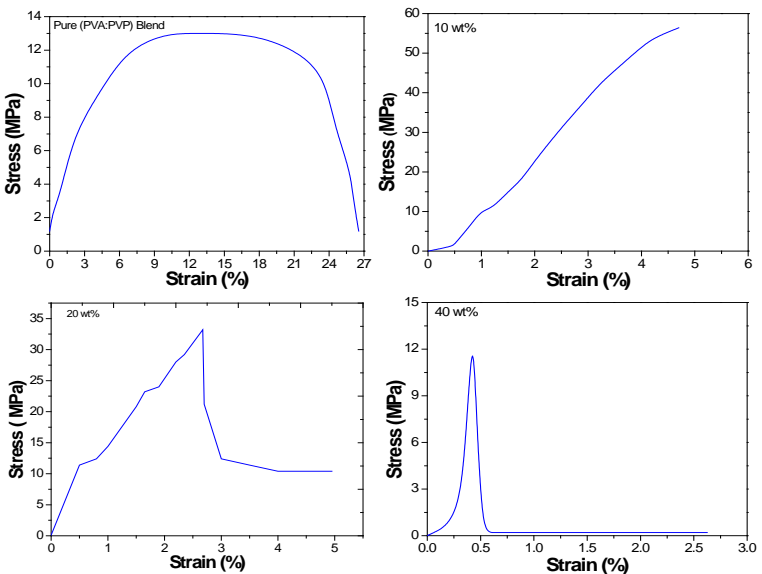

Figure 5: Stress-strain curves of pure and PVA:PVP polymer blend films reinforced with different weight ratios of $\mathrm{CdCl}_{2} \cdot \mathrm{H}_{2} \mathrm{O}$ salt.

at different weight ratios (10 wt\%, $20 \mathrm{wt} \%, 40 \mathrm{wt} \%)$ at room temperature and within the frequency range of $100 \mathrm{~Hz}-1 \mathrm{MHz}$, as shown in Fig. 4. It is clear that the alternating electrical conductivity increases significantly as the frequency increases for all the polymer blend films, and this increase is due to increased polarization in the samples [15]. It should be noted that the alternating electrical conductivity in a dielectric material is the amount of power lost when an alternating electric field is exerted, which appears as heat when the dipoles rotate in their positions. The vibration of the charges changes with the alternating electric field, and therefore depends on the frequency [16]. Moreover, the alternating electrical conductivity at the same frequency increases with an increase in the weight ratio of added salt. This increase is strongly affected by many factors, including the purity of the material and dispersion. In general, this increase in alternating electrical conductivity is attributed to a decrease in dielectric resistance due to the increase of conductive molecules in the polymeric blend films [17], and also because of the number of charge carriers that have a significant relaxation time due to the high energy barrier [18].

\section{ii. Mechanical properties \\ a. Tensile test}

The tensile test was conducted and stress-strain curves were obtained for pure PVA:PVP polymer blend films and polymer blend films reinforced by $\mathrm{CdCl}_{2} \cdot \mathrm{H}_{2} \mathrm{O}$ salt at different weight ratios $(10 \mathrm{wt} \%$, $20 \mathrm{wt} \%, 40 \mathrm{wt} \%)$. These curves are shown in Fig. 5. The stress-strain of the pure polymer blend films consists of the elastic deformation region showing a linear relationship between stress and strain. From this region Young's modulus can be estimated from the slope of the straight line. The polymeric material within the boundaries of this region suffers from an elastic deformation due to the stretching and elongation of the polymeric chains without breaking the bonds. This curve deviates from linear behavior due to cracks generated within the polymeric material. These cracks grow and combine with increased stress, creating larger incisions and continuing to grow with stress until a fracture occurs in the sample [19]. In other cases, the fracture begins at the outer surfaces in the sites of deformities or defects such as scratches, holes or internal cracks, which act as areas for concentration of stress. This leads to a rise in the stress value to limits where the strength value exceeds the internal force of cohesion, and thus breakage occurs.

When the $\mathrm{CdCl}_{2} \cdot \mathrm{H}_{2} \mathrm{O}$ salt is added to the pure polymer blend, the stress-strain curve changes and we obtain curves with different properties. Figures 6, 7 and 8 show the variations in tensile strength,

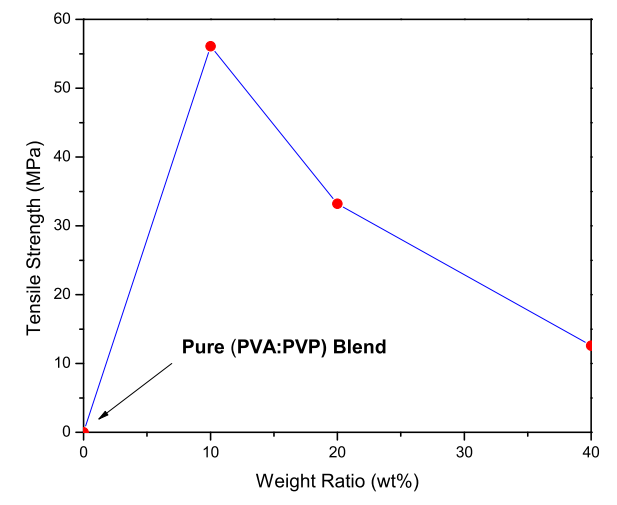

Figure 6: Tensile strength of pure and PVA:PVP polymer blend films reinforced with different weight ratios of $\mathrm{CdCl}_{2} \cdot \mathrm{H}_{2} \mathrm{O}$ salt. 
Papers in Physics, vol. 12, ART. 120006 (2020) / R. S. Mahmood et al.

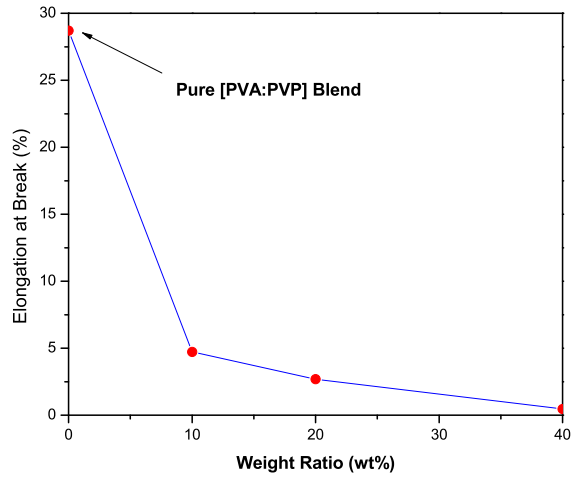

Figure 7: Elongation at break of pure and PVA:PVP polymer blend films reinforced with different weight ratios of $\mathrm{CdCl}_{2} \cdot \mathrm{H}_{2} \mathrm{O}$ salt.

elongation at break and Young's modulus as a function of the weight ratio of the added salt, for all samples. Table 1 shows the values of tensile strength, elongation at break and Young's modulus for all polymer films, determined from the stress-strain curves. The tensile strength of the pure polymer blend films is $15.5 \mathrm{MPa}$, the elongation at break value is $28.7 \%$ and the value of Young's modulus is $332 \mathrm{MPa}$; however, when the blend is reinforced with $\mathrm{CdCl}_{2} \cdot \mathrm{H}_{2} \mathrm{O}$ salt, these values change. The tensile strength values increase at the $10 \mathrm{wt} \%$ weight ratio, reaching $56.1 \mathrm{MPa}$, and then decrease with an increase in the weight ratio of the salt added. The elongation at break value starts to decrease with an increase in the weight ratio of salt added, while the value of Young's modulus starts to increase unsystematically to reach its highest value of $7200 \mathrm{MPa}$ at the weight ratio of $40 \mathrm{wt} \%$. The decrease observed in the values of tensile strength, elongation at break and Young's modulus for polymer blend films at some weight ratios of salt reinforcement compared with pure polymer film is due to weak interaction between the molecules and low interstitial adhesion between the composite components, which leads to an increase in the composite fragility [20].

The increase found in the values of tensile strength, elongation at break and Young's modulus for the polymer blend films at some weight ratios of salt reinforcement compared with pure polymer film indicates that reinforcement has been achieved. It can be concluded that, at these weight ratios,

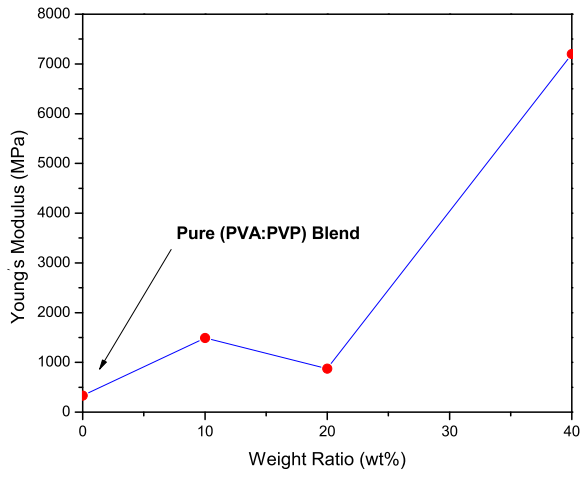

Figure 8: Young's modulus of pure and PVA:PVP polymer blend films reinforced with different weight ratios of $\mathrm{CdCl}_{2} \cdot \mathrm{H}_{2} \mathrm{O}$ salt.

the added salt is compatible with common addition polymerization and is effectively dispersed in the polymer blend, affecting its mechanical properties [21].

\section{b. Hardness test}

Hardness (shore D) for pure polymer blendfilms and those reinforced by $\mathrm{CdCl}_{2} \cdot \mathrm{H}_{2} \mathrm{O}$ salt are shown in Fig. 9. It is clear from the figure that the hardness of the pure polymer blend films increases with an increase in the weight ratio of salt added, reaching its highest value (32.5) at the $20 \mathrm{wt} \%$ weight ratio, and then the hardness decreases with an increase in the weight ratio of salt added. This decrease is due to the high viscosity gained by the prepared material when adding high weight ratios of reinforcing salt to the matrix (polymer blend), which is in the liquid state. The high viscosity makes penetration of the $\mathrm{CdCl}_{2} \cdot \mathrm{H}_{2} \mathrm{O}$ salt inside the interfaces of the polymer blend inefficient and dif-

Table 1: Tensile property values of pure and PVA:PVP polymer blend films reinforced with different weight ratios of $\mathrm{CdCl}_{2} \cdot \mathrm{H}_{2} \mathrm{O}$ salt.

\begin{tabular}{cccc}
\hline \hline $\begin{array}{c}\text { Weight Ratio of Salt } \\
\text { (wt \%) }\end{array}$ & $\begin{array}{c}\text { Tensile Strength } \\
(\mathrm{MPa})\end{array}$ & $\begin{array}{c}\text { Elongation at } \\
\text { Break (\%) }\end{array}$ & $\begin{array}{c}\text { Young's Modulus } \\
(\mathrm{MPa})\end{array}$ \\
\hline Pure & & & \\
(PVA:PVP) & 15.5 & 28.7 & 332 \\
10 & 56.1 & 4.72 & 1490 \\
20 & 33.2 & 2.69 & 873 \\
40 & 12.6 & 0.451 & 7200 \\
\hline \hline
\end{tabular}


PAPERs In Physics, vol. 12, ART. 120006 (2020) / R. S. Mahmood et al.

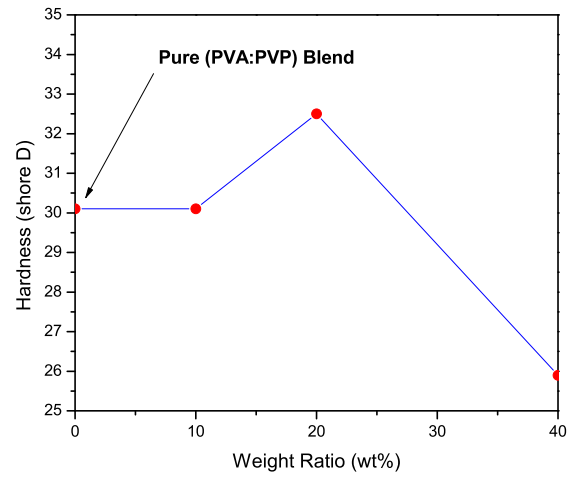

Figure 9: Hardness of pure and PVA:PVP polymer blend films reinforced with different weight ratios of $\mathrm{CdCl}_{2} \cdot \mathrm{H}_{2} \mathrm{O}$ salt.

ficult, which leads to the production of many gaps within the prepared composite material when hardened, causing a decrease in the hardness [22]. Table 2 shows the hardness values of all polymer blend films.

\section{c. Impact test}

The impact test is an important mechanical test used to demonstrate the resistance of a material to collapse by the force of impact under operating conditions, as it measures the actual energy required to break a piece under the test [23].

Fracture Energy for pure polymer blend films and those reinforced by $\mathrm{CdCl}_{2} \cdot \mathrm{H}_{2} \mathrm{O}$ salt were recorded at different weight ratios, as shown in Fig. 10.

It can be seen that the fracture energy value for the pure polymer blend films is $0.392 \mathrm{~kg} . \mathrm{m}^{2} / \mathrm{s}$, and that this value increases as the weight ratio of added salt increases. In other words, the fig-

Table 2: Hardness values of pure and PVA:PVP polymer blend films reinforced with different weight ratios of $\mathrm{CdCl}_{2} \cdot \mathrm{H}_{2} \mathrm{O}$ salt.

\begin{tabular}{cc}
\hline \hline $\begin{array}{c}\text { Weight Ratio of Salt } \\
\text { (wt \%) }\end{array}$ & $\begin{array}{c}\text { Hardness } \\
\text { (Shore D) }\end{array}$ \\
\hline Pure (PVA:PVP) & 30.1 \\
10 & 30.1 \\
20 & 32.5 \\
30 & 25.9 \\
\hline \hline
\end{tabular}

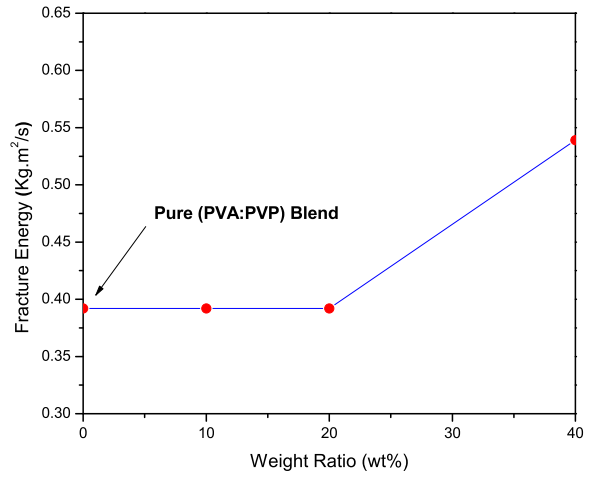

Figure 10: Fracture energy of pure and PVA:PVP polymer blend films reinforced with different weight ratios of $\mathrm{CdCl}_{2} \cdot \mathrm{H}_{2} \mathrm{O}$ salt.

ure shows that the absorbed energy necessary for fracture increases with an increase in the weight fracture [24], where the $\mathrm{CdCl}_{2} \cdot \mathrm{H}_{2} \mathrm{O}$ salt works to hinder the growth of the crack, and this changes the shape of the crack and its direction. This change in the shape of the crack increases the surface area of the fracture and the spent energy, all of which lead to an increase in the mechanical resistance of the material [25].

The addition of $\mathrm{CdCl}_{2} \cdot \mathrm{H}_{2} \mathrm{O}$ salt to the PVA:PVP pure polymer blend film improved the mechanical properties. The reason for the increase in fracture energy with the increase in the weight ratio of added salt is that a large part of the impact energy projected onto the sample is reduced by the salt, which increases the resistance of the substance [25]. Table 3 shows the fractional energy values of all polymeric films.

Table 3: Fracture energy values of pure and PVA:PVP polymer blend films reinforced with different weight ratios of $\mathrm{CdCl}_{2} \cdot \mathrm{H}_{2} \mathrm{O}$ salt.

\begin{tabular}{cc}
\hline \hline $\begin{array}{c}\text { Weight Ratio of Salt } \\
\text { (wt \%) }\end{array}$ & $\begin{array}{c}\text { Fracture Energy } \\
\left(\mathrm{kg} \cdot \mathrm{m}^{2} / \mathrm{s}\right)\end{array}$ \\
\hline (PVA:PVP) & 0.392 \\
10 & 0.392 \\
20 & 0.392 \\
40 & 0.539 \\
\hline \hline
\end{tabular}


PAPERs In Physics, vol. 12, ART. 120006 (2020) / R. S. Mahmood et al.

\section{Conclusions}

The results for polymer blend films reinforced with $\mathrm{CdCl}_{2} \cdot \mathrm{H}_{2} \mathrm{O}$ salt show that the values of the dielectric constant, loss factor, and alternating electrical conductivity increase with an increase in the weight ratio of $\mathrm{CdCl}_{2} \cdot \mathrm{H}_{2} \mathrm{O}$ salt at the same frequency. In general, this increase is attributed to an increase in polarization. This is why all these polymer blends can be used in the manufacture of electric batteries.

The results of the tension test for PVA:PVP polymer blend films reinforced with $\mathrm{CdCl}_{2} \cdot \mathrm{H}_{2} \mathrm{O}$ salt show a change in the values of tensile strength, elongation at break and Young's modulus as the salt weight ratio increases. It can be concluded that, at these weight ratios, the added salt is compatible with common addition polymerization and is effectively dispersed in the polymer blend, affecting its mechanical properties. The hardness value first increases then decreases as the salt weight ratio increases. This decrease is due to the high viscosity gained by the prepared material when adding high weight ratios of reinforcing salt to the matrix (polymer blend), which is in the liquid state. The fracture energy value increases with increasing salt weight ratio, where the salt works to hinder the groh of the crack and this changes the shape of the crack and its direction. This change in the shape of the crack increases the surface area of the fracture and the spent energy, all of which lead to an increase in the mechanical resistance of the material, thus they could be good candidates for hard adhesives with low flexibility.

[1] S A Salman, N A Bakr, S S Abduallah, Study of thermal decomposition and FTIR for PVA$\mathrm{AlCl}_{3}$ composite films, J. Eng. Appl. Sci. 14, 717 (2019).

[2] S A Salman, N A Bakr, M R Jwameer, Effect of annealing on the optical properties of (PVA$\mathrm{CuCl}$ ) composites, Int. Lett. Chem. Phys. Astron. 63, 98 (2016).

[3] B Lobo, M R Ranganath, T S G Ravi Chandran, G Venugopal Rao, V Ravindrachary, S Gopal, Iodine-doped polyvinylalcohol using positron annihilation spectroscopy, Phys. Rev. B 59, 13693 (1999).
[4] L M Robeson, Polymer Blends Handbook, Springer-Kluwer Academic Publishers, Netherlands (2003).

[5] J R Fried, Polymer Science and Technology, Prentice Hall Inc., Upper Saddle Rivers, New Jersey (2014).

[6] R Singh, S G Kulkarni, Morphological and mechanical properties of Poly(Vinyl Alcohol) doped with inorganic fillers, Int. J. Polym. Mater. Po. 62, 351 (2013).

[7] P J Liu, W H Chen, Y Liu, S B Bai, Q Wang, Thermal melt processing to prepare halogen-free flame retardant Poly(Vinyl Alcohol), Polym. Degrad. Stabil. 109, 261 (2014).

[8] R S Mahmood, S A Salman, N A Bakr, Optical, thermal properties of cadmium chloride reinforced PVA:PVP blend films, Journal of Polymer \& Composites 8, 46 (2020).

[9] B H Rabee, A Hashim, Synthesis and characterization of carbon nanotubes-polystyrene composites, Eur. J. Sci. Res. 60, 247 (2011).

[10] G C Psarras, K G Gatos, P K Karahaliou, S N Georga, C A Krontiras, J Karger-Kocsis, Relaxation phenomena in rubber/layered silicate nanocomposites, eXPRESS Polymer Letters 1 , 837 (2007).

[11] SK S Basha, M Gnanakiran, B R Kumar, K V B Reddy, M V B Rao, M C Rao, Synthesis and spectral characterization on PVA/PVP: Go based blend polymer electrolytes, Rasayan J. Chem. 10, 1159 (2016).

[12] S B Aziz, O Gh Abdullah, S A Hussein, H M Ahmed, Effect of PVA blending on structural and ion transport properties of CS:AgNt-Based polymer electrolyte membrane, Polymers 9, 622 (2017).

[13] F T M Noori, E M Mehdi, Plasma effect on AC electrical properties of ( $\mathrm{PVA}-\mathrm{PVP}-\mathrm{MnO}_{2}$ ) nano composites for piezoelectric application, Int. J. Sci. Res. 7, 483 (2018). 
Papers in Physics, vol. 12, ART. 120006 (2020) / R. S. Mahmood et al.

[14] K K Verma, M S Alam, R K Sinha, R K Shukla, Dielectric, electrical and microstructural properties of unfilled and MWCNTs filled polystyrene nanocomposite prepared by in-situ polymerization technique using ultrasonic irradiation, Indian J. Pure Ap. Phy. 52, 614 (2015).

[15] M T Ramesan, V K Athira, P Jayakrishnan, C Gopinathan, Preparation, characterization, electrical and antibacterial properties of sericin/poly(vinyl alcohol)/poly(vinyl pyrrolidone) composites, J. Appl. Polym. Sci. 133, 43535 (2016).

[16] R Popielarz, C K Chiang, R Nozaki, J Obrzut, Dielectric properties of polymer/ferroelectric ceramic composites from $100 \mathrm{~Hz}$ to $10 \mathrm{GHz}$, Macromolecules 34, 5910 (2001).

[17] S M M Stowe, Ph.D. Thesis, Department of Physics, University of Baghdad Faculty of Education - Ibn Al-Haitham, Baghdad (2005).

[18] M B Nanda Prakash, A Manjunath, R Somashekar, Studies on AC electrical conductivity of $\mathrm{CdCl}_{2}$ doped PVA polymer electrolyte, Adv. Cond. Matter Phys. 2013, 1 (2013).

[19] X D Yu, M Malinconico, E Martuscelli, Highly filled particulate composites enhancement of performances by using compound coupling agents, J. Mater. Sci. 25, 3255 (1990).
[20] C Ravindra, M Sarswati, G Sukanya, P Shivalila, Y Soumya, K Deepak, Tensile and thermal properties of poly (vinyl pyrrolidone)/vanillin incorporated poly (vinyl alcohol) films, Res. J. Physical Sci. 3, 1 (2015).

[21] Y Luo, X Jiang, W Zhang, X Li, Effect of aluminium nitrate hydrate on the crystalline, thermal and mechanical properties of poly(vinyl alcohol) film, Polym. Polym. Compos. 23, 555 (2015).

[22] S I Salih, K M Shabeeb, Q A Hamad, Studying mechanical properties for polymer matrix composite material reinforced by fibers and particles, J. Tech. Univ. 4, 81 (2010).

[23] M C Gupta, A P Gupta, Polymer Composite, New Age International Publishers, New Delhi (2005).

[24] A M Abdullah, A M Hashim, A J Bader, Effect of alumina particles on the mechanical properties of discontinuous glass fiber reinforced unsaturated polyester composites, Al-Qadisiyah Journal for Engineering Sciences 4, 170 (2011).

[25] A A Al-Jubouri, A I Al-Mousawi, KH A Ismail, A J Salman, Effect of reinforcing by magnesium oxide particles on thermal conductivity and mechanical properties of vinyl ester resin polymer composite, J. Karbala Univ. Special Issue - 6th. Scientific Conference, 26 (2010). 